\title{
Plasma cholesterol and other cardiac risk factors in adolescent girls
}

\author{
M A Bermingham, E Jones, K Steinbeck, K Brock
}

\begin{abstract}
The aim was to examine the effects of smoking, physical activity, and body mass on total cholesterol and high density lipoprotein cholesterol (HDL-C) in adolescent schoolgirls in Sydney, Australia. Body mass index (BMI) and waist to hip ratio (WHR) were determined in 144 girls aged 15 to 18 years. Total cholesterol (TC) and HDL-C were estimated on fingerprick blood and behavioural variables assessed by questionnaire. Prevalence of overweight (>90th centile for BMI) was less in Australian adolescents than reported from the USA. Smokers had lower total cholesterol than non-smokers; this was partly explained by a lower HDL-C in the smokers. Physical activity was associated with a less atherogenic TC/HDL-C ratio. Girls with BMI >90th centile had higher mean TC/HDL-C and apoprotein $B$ than the group as a whole but those >90th centile for WHR did not.
\end{abstract}

(Arch Dis Child 1995; 73: 392-397)

Keywords: adolescents, anthropometry, cholesterol.

There are many reasons for examining cardiac risk factors in adolescent girls. While epidemiological studies show that plasma cholesterol concentrations in the young predict adult values, ${ }^{1}$ females aged 16 to 18 years have not been extensively studied in surveys of disease risk factors in Australia. Early studies included the measurement of total plasma cholesterol and triglyceride in boys only, ${ }^{2}$ total cholesterol and high density lipoprotein cholesterol (HDL-C) measured in Adelaide schoolchildren aged 8 to 17 years, ${ }^{3}$ and large studies such as the Australian Council on Health, Physical Education and Recreation (ACHPER) survey ${ }^{4}$ of Australian schoolchildren, which did not sample beyond age 15. A study of total cholesterol in Western Australia ${ }^{6}$ examined children aged 10 to 12 only, and The National Heart Foundation risk factor prevalence studies (NHFRFPS) ${ }^{78}$ span the ages 20 to 69 years.

Cholesterol in blood is distributed between various lipoprotein fractions. ${ }^{9}$ Raised concentrations of certain of these fractions such as low density lipoprotein (LDL), which has apoprotein
B (apo B) as its protein moiety, are associated with increased risk of coronary heart disease, while HDL-C, which has apoprotein A-1 (apo A1) as its protein moiety, is protective. ${ }^{10}$ The analysis of the various fractions is a more useful indicator of coronary heart disease risk status in populations than that of total cholesterol alone ${ }^{11}$; the ratio of total cholesterol to HDL-C (TC/HDL-C) is inversely related to risk of coronary heart disease and is a predictor of coronary heart disease independent of age, smoking, body mass index (BMI), and history of angina, diabetes, or hypertension. ${ }^{12}$ Measurements of apo Al and B also add significantly to the prediction of coronary heart disease risk. ${ }^{13}$

Cigarette smoking causes unfavourable alterations in plasma lipids, particularly a reduction in HDL-C, ${ }^{14-16}$ but these findings have not been confirmed in adolescents. While smoking is decreasing in the adult population in Australia, ${ }^{17} 28 \%$ to $31 \%$ of 15 to 17 year old girls in NSW currently smoke; this rate has remained relatively stable over six years despite extensive public education campaigns. ${ }^{18}$ The estimated risk of premature death in a 15 year old from ever having smoked is $11.9 \% .^{19}$

HDL-C is increased by physical activity. ${ }^{20}$ Physical fitness is associated with a reduction in the TC/HDL-C ratio ${ }^{21}$ and is positively correlated with HDL-C concentrations in adults, ${ }^{22-24}$ but this relation has not always been found ${ }^{25} 26$ and adolescents have not been investigated. Australian girls aged 9 and 10 were found to be less fit and fatter than boys, ${ }^{27}$ and girls have generally given up formal sporting activities by early high school.

Generalised obesity is associated with an adverse lipid profile, ${ }^{28}$ as is an abdominal pattern of body fat distribution. ${ }^{29-34}$ In adults, abdominal fat is closely associated with an adverse blood lipid profile, including reduced HDL-C ${ }^{35}$ and an increased incidence of coronary heart disease. ${ }^{36}$ These associations have not been investigated in younger age groups. Australian schoolchildren from Mediterranean or Middle Eastern families are fatter than other groups 3738 and are perceived to be less likely to participate in school sport.

The aim of this study was therefore to examine the associations between body mass, smoking, physical activity and the concentrations of total cholesterol and HDL-C in adolescent schoolgirls. 
Table 1 Characteristics of the study population by major age group. Values are mean (SD)

\begin{tabular}{|c|c|c|c|c|}
\hline & \multicolumn{3}{|l|}{ Age (years) } & \multirow[b]{2}{*}{$\begin{array}{l}\text { Total group } \\
144 \Phi\end{array}$} \\
\hline & $\begin{array}{l}15 \\
(n=25)\end{array}$ & $\begin{array}{l}16 \\
(n=85)\end{array}$ & $\begin{array}{l}17 \\
(n=32)\end{array}$ & \\
\hline $\begin{array}{l}\text { Weight (kg) } \\
\text { Height (cm) } \\
\text { BMI }\end{array}$ & $\begin{array}{c}59 \cdot 3(10 \cdot 70) \\
163 \cdot 5(7 \cdot 2) \\
22 \cdot 16(3 \cdot 4)\end{array}$ & $\begin{array}{c}58 \cdot 0(8 \cdot 30) \\
163 \cdot 4(6 \cdot 1) \\
21 \cdot 67(2 \cdot 5)\end{array}$ & $\begin{array}{c}56 \cdot 9(7 \cdot 7) \\
163 \cdot 3(7 \cdot 4) \\
21 \cdot 29(2 \cdot 5)\end{array}$ & $\begin{array}{c}57 \cdot 9(8 \cdot 7) \\
163.3(6.5) \\
21.65(2 \cdot 65)\end{array}$ \\
\hline $\begin{array}{l}\text { Waist (cm) } \\
\text { Hips (cm) } \\
\text { WHR }\end{array}$ & $\begin{array}{l}70.3(8 \cdot 3) \\
96 \cdot 0(8 \cdot 4) \\
0.73(0.05)\end{array}$ & $\begin{array}{l}68.9(5.3) \\
93.90(6.5) \\
0.73(0.05)\end{array}$ & $\begin{array}{l}67 \cdot 4(5 \cdot 5) \\
93.0(5 \cdot 9) \\
0.73(0.04)\end{array}$ & $\begin{array}{l}68 \cdot 8(5 \cdot 9) \\
94 \cdot 0(6.7) \\
0.73(0.05)\end{array}$ \\
\hline $\begin{array}{l}\text { SBP }(\mathrm{mm} \mathrm{Hg}) \\
\mathrm{DBP}(\mathrm{mm} \mathrm{Hg})\end{array}$ & $\begin{array}{c}111 \cdot 1(9 \cdot 1) \\
71 \cdot 10(8 \cdot 5)\end{array}$ & $\begin{array}{c}109 \cdot 9(9 \cdot 3) \\
70 \cdot 80(9 \cdot 3)\end{array}$ & $\begin{array}{c}109.9(8 \cdot 7) \\
71.00(8 \cdot 5)\end{array}$ & $\begin{array}{c}110.0(9.09) \\
70.91(8.92)\end{array}$ \\
\hline $\begin{array}{l}\% \text { BMI >90th centile } \\
\% \text { Smoking } \\
\% \text { NESB }\end{array}$ & $\begin{array}{r}12 \\
4 \\
20\end{array}$ & $\begin{array}{l}10 \\
15 \\
22\end{array}$ & $\begin{array}{r}9 \\
25 \\
28\end{array}$ & $\begin{array}{l}9 \cdot 7 \\
15 \cdot 3 \\
25\end{array}$ \\
\hline
\end{tabular}

${ }^{\star} \mathrm{BMI}=$ body mass index; $\mathrm{WHR}=$ waist to hip ratio; $\mathrm{SBP}=$ systolic blood pressure; $\mathrm{DBP}=$ diastolic blood pressure; NESB=non-English speaking background.

Two 18 year old girls were included in the total group.
Twe

\section{Methods}

SUBJECTS AND STUDY DESIGN

This was a cross sectional epidemiological study. The study population consisted of girls in the fourth and fifth years of secondary school in the Sydney Metropolitan area. A sample stratified by socioeconomic level was chosen using six schools in different areas of Sydney. Two schools had populations of predominantly non-English speaking background and four were mainly of English speaking background. Five schools were single sex and one was coeducational. Schools were approached by letter, and permission to recruit in each school was obtained from the principal. Follow up discussions on the relation between cholesterol, diet, and coronary heart disease in the presence of a trained nutritionist were offered, and accepted by some schools. Ethics approval was obtained from the University of Sydney ethics committee, and a consent form was signed by each girl and her parent or guardian.

For cardiovascular risk factor assessment, a questionnaire based on the MONICA survey (an international study monitoring coronary heart disease risk factors in adults in various countries) was adapted for use in schools and validated by a pilot survey on 20 subjects. Date of birth was recorded and questions asked on smoking and diet, alcohol intake, and first language spoken at home. Physical activity was assessed as (1) hours spent at exercise (both vigorous and non-vigorous) in the previous two weeks; (2) total number of exercise sessions (both vigorous and non-vigorous) in the previous two weeks; (3) walking for exercise; (4) the response to a single

Table 2 Comparison of body mass index values $\left(\mathrm{kg} / \mathrm{m}^{2}\right)$ from this study with $A C H P E R$ and NHANES data

\begin{tabular}{lllllll}
\hline \multirow{2}{*}{$\begin{array}{l}\text { Age } \\
\text { Study group }\end{array}$} & \multicolumn{6}{l}{ Centile bands } \\
\cline { 3 - 7 } & years) & 10 & 25 & 50 & 75 & 90 \\
\hline This study & 15 & $17 \cdot 90$ & $18 \cdot 90$ & $21 \cdot 60$ & $\mathbf{2 4 \cdot 1 0}$ & $\mathbf{2 7} \cdot 80$ \\
ACHPER & 15 & $18 \cdot 00$ & $19 \cdot 10$ & $20 \cdot 70$ & $\mathbf{2 2} \cdot 60$ & $25 \cdot 10$ \\
NHANES & 15 & $16 \cdot 80$ & $18 \cdot 00$ & $19 \cdot 90$ & $22 \cdot 40$ & $26 \cdot 00$ \\
This study & 16 & $18 \cdot 60$ & $20 \cdot 00$ & $21 \cdot 50$ & $22 \cdot 90$ & $25 \cdot 10$ \\
NHANES & 16 & $17 \cdot 10$ & $18 \cdot 40$ & $20 \cdot 20$ & $22 \cdot 80$ & $26 \cdot 50$ \\
This study & 17 & $18 \cdot 20$ & $19 \cdot 70$ & $21 \cdot 30$ & $22 \cdot 70$ & $24 \cdot 30$ \\
NHANES & 17 & $17 \cdot 60$ & $18 \cdot 90$ & $20 \cdot 70$ & $23 \cdot 13$ & $27 \cdot 10$ \\
\hline
\end{tabular}

question, 'Do you currently participate in any regular activity or programme designed to improve or maintain your physical fitness?'; and (5) an activity score based on time and sessions spent at both vigorous and nonvigorous exercise, walking, and participation in an activity programme (maximum score 12 points). After discussion with some teachers and parents, it was thought inappropriate to ask questions about pubertal status or oral contraceptive use.

\section{ANTHROPOMETRIC AND BLOOD PRESSURE} MEASUREMENTS

Anthropometric measurements were taken with the subject in light summer clothing without shoes. Height was measured with a wall mounted rigid tape and weight with a portable electronic scales, calibrated before each session against a standard laboratory beam balance. Weight and height were measured by the same observer. A body mass index $(\mathrm{BMI}=$ weight $\mathrm{kg} /$ height $\mathrm{m}^{2}$ ) was calculated. Body girths were measured with a plastic tape measure at the widest protrusion of the gluteal muscles (hip) and at the smallest girth between the bottom of the rib cage and the iliac crest (waist) with the subjects standing. A waist to hip ratio (WHR) was calculated. Body girths were measured by either of two people who standardised measurements against each other before the study. Blood pressure was measured with an Omron automatic blood pressure machine.

\section{BIOCHEMICAL MEASUREMENTS}

Blood samples of up to $1 \mathrm{ml}$ were obtained by a finger prick with an 'Autolancet' followed by gentle massage. Blood was collected directly into $2 \mathrm{ml}$ plastic Sarsdet EDTA tubes which were drawn out to a fine capillary at one end. If insufficient blood was obtained, a second finger was pricked only if the subject was willing and not distressed by the first. The tubes were then placed inside larger tubes and centrifuged at $2000 \mathrm{~g}$ for seven minutes to obtain plasma. Total cholesterol and HDL-C were determined within 12 hours on a Reflotron reflectance photometric analyser. ${ }^{3940}$ When sufficient plasma was available, apo A1 and apo B were measured on a Turbitimer (Behring). The investigators are participating members in the Royal College of Pathologists of Australia quality assurance programme 'Lipids', and the measurements were within the recommended limits in comparison with the reference method.

\section{STATISTICAL ANALYSIS}

The Statsveiw 4.02 package for Macintosh was used to analyse the raw data. ${ }^{41}$ All the variables with the exception of BMI were approximately normally distributed. Student's $t$ test for unpaired data was used to compare means. Lipid values were adjusted for waist, BMI, and WHR by entering each lipid measurement as a dependent variable in a multiple linear regression equation with waist, BMI, and 
Table 3 Anthropometric measurements stratified by smoking, first language spoken at home, and various measures of physical activity

\begin{tabular}{|c|c|c|c|c|c|}
\hline & \multirow[b]{2}{*}{ No } & \multicolumn{2}{|l|}{$B M I$} & \multicolumn{2}{|l|}{ WHR } \\
\hline & & Mean & $S D$ & Mean & $S D$ \\
\hline \multicolumn{6}{|l|}{ Smoker } \\
\hline $\begin{array}{l}\text { No } \\
\text { Yes } \\
\text { Difference (SEM) }\end{array}$ & $\begin{array}{r}122 \\
22\end{array}$ & $\begin{array}{l}21.55 \\
22.20 \\
0.65(0.61)\end{array}$ & $\begin{array}{l}2 \cdot 67 \\
2 \cdot 52\end{array}$ & $\begin{array}{l}0.732 \\
0.741 \\
0.009(0.011)\end{array}$ & $\begin{array}{l}0.05 \\
0.05\end{array}$ \\
\hline \multicolumn{6}{|c|}{ English speaking background } \\
\hline Yes & 109 & $21 \cdot 65$ & $2 \cdot 70$ & $0 \cdot 728^{\star}$ & 0.05 \\
\hline No & 35 & $21 \cdot 65$ & 2.53 & $0 \cdot 749$ * & 0.05 \\
\hline Difference (SEM) & & $0.00(0.51)$ & & $0.021(0.009)$ & \\
\hline \multicolumn{6}{|l|}{ Hours exercise $/ 2$ weeks } \\
\hline$>$ Average & 55 & $21 \cdot 93$ & $2 \cdot 41$ & 0.725 & 0.05 \\
\hline$<$ Average & 89 & $21 \cdot 48$ & $2 \cdot 78$ & 0.739 & 0.05 \\
\hline Difference (SEM) & & $0.45(0.45)$ & & $0.013(0.01)$ & \\
\hline \multicolumn{6}{|l|}{ Sessions exercise/2 weeks } \\
\hline$>$ Average & 61 & $21 \cdot 80$ & 2.55 & 0.738 & 0.05 \\
\hline$<$ Average & 83 & $21 \cdot 55$ & $2 \cdot 73$ & $0 \cdot 730$ & 0.05 \\
\hline Difference (SEM) & & $0.25(0.45)$ & & $0.007(0.008)$ & \\
\hline \multicolumn{6}{|c|}{ Regular activity programme? } \\
\hline Yes & 95 & $21 \cdot 74$ & $2 \cdot 62$ & 0.733 & $0 \cdot 05$ \\
\hline No & 47 & 21.56 & $2 \cdot 75$ & 0.737 & 0.04 \\
\hline Difference (SEM) & & $0.18(0.48)$ & & $0.004(0.009)$ & \\
\hline \multicolumn{6}{|l|}{ Activity score $(\max =12)$} \\
\hline Top scorers $(9-12)$ & 33 & $21 \cdot 86$ & $2 \cdot 87$ & 0.722 & 0.05 \\
\hline Bottom scorers $(0-3)$ & 20 & $21 \cdot 16$ & $2 \cdot 30$ & 0.730 & 0.04 \\
\hline Difference (SEM) & & $0.70(0.76)$ & & $0.008(0.013)$ & \\
\hline
\end{tabular}

$\star$ Significant difference at 0.05 level.

WHR as independent variables, and then entering the coefficients in the equation to obtain corrected values. ${ }^{42}$

\section{Results}

Questionnaires were administered and anthropometric and blood pressure measurements taken on a total sample of 144 girls from six schools. At any one school, either the fourth or the fifth year was available to participate on the particular sampling day at that school. The estimated response rate was $72 \%$. Subjects were predominantly aged 15 to 17 but two 18 year olds volunteered and were included. The average age of girls from English speaking and non-English speaking backgrounds was 16.03 and $16 \cdot 23$ years, respectively. Girls with a nonEnglish speaking background tended to be distributed in the older age groups.

Anthropometric and blood pressure measurements of the total group and of each of the major age groups are shown in table 1 . The mean BMI of each major age group is shown, and also the proportion of subjects who are above the 90th centile for BMI in each age group. The mean WHR of the total group was 0.73 and this did not vary across age groups. Blood pressure also remained relatively constant across age groups. The systolic blood pressure was similar to that of 15 year olds in

Table 4 Physical activity profile stratified by smoking and first language spoken

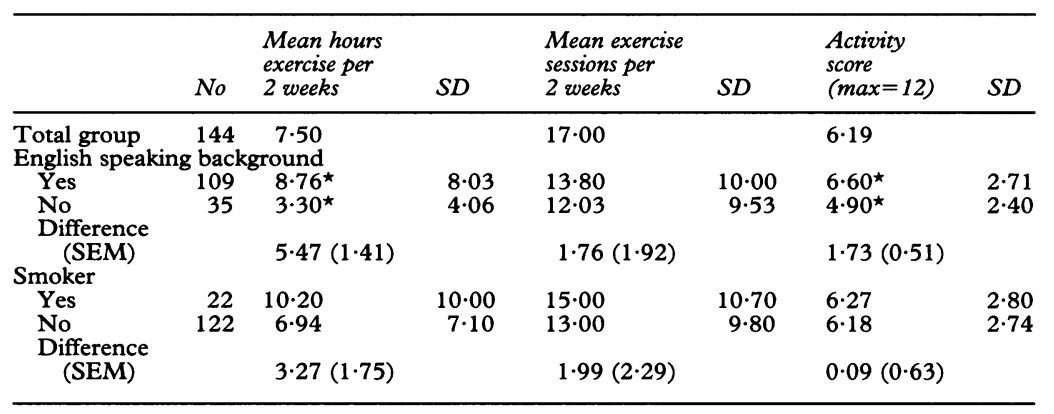

${ }^{\star} \mathrm{p}<0 \cdot 01$. the ACHPER survey, ${ }^{4}$ and the diastolic blood pressure was approximately $10 \mathrm{~mm} \mathrm{Hg}$ lower. The proportion of girls who smoked increased with age, as did the proportion of girls of nonEnglish speaking background. The duration of smoking ranged from 1 to 4 years with an average of 1.5 years.

The anthropometric data were compared with data on 15 year olds from the ACHPER survey, ${ }^{4}$ and on 15 to 17 year olds from the large nationally representative US survey NHANES $I^{4344}$ (table 2). In the 16 and 17 year age group Americans were heavier than Australians at the 90th centile. Comparison of our BMI distributions with the NHANES data shows that in the latter the distributions shift slightly upwards with age; the Australian distributions behave differently, the medians remaining almost constant but the variability decreasing markedly (the distances from the 10 th to the 90 th centile are $9 \cdot 9,6 \cdot 5$, and $6 \cdot 1$, as opposed to $9 \cdot 2,9 \cdot 4$, and $9 \cdot 5$ for NHANES).

A comparison of the anthropometric measurements stratified by smoking, first language spoken at home, and measures of physical activity is shown in table 3 . Smokers and non-smokers showed no significant differences but there was a trend towards a higher BMI and a more central distribution of body fat in smokers. Girls of non-English speaking background also had a more central distribution of body fat, with a significantly higher WHR. When the vigorous and nonvigorous exercise categories were collapsed and subjects who were either above or below the the mean by the various methods of assessing physical activity (including a comparison of top and bottom scorers on the activity scale) were compared, no differences were apparent in the anthropometric measurements.

No difference in overall physical activity was observed in smokers compared with nonsmokers (table 4). Girls of non-English speaking background had a significantly lower activity score $(4.9 v 6.6, \mathrm{p}<0.001)$ and spent fewer total hours at exercise $(3.3 v 8.8$, $\mathrm{p}<0.001)$. It appeared that smoking was associated with ethnicity as the percentage of girls from English speaking backgrounds who smoked was twice that of girls from nonEnglish speaking backgrounds (although the total number of smokers in the latter category was small at 3/35).

\section{LIPID ANALYSIS}

Sufficient blood was obtained to measure total cholesterol in 144, total cholesterol and HDL-C in 125, and total cholesterol, HDL-C, apo $\mathrm{A} 1$, and apo $\mathrm{B}$ in 53 subjects. The mean lipid values of the total group and of each major age group are shown in table 5 . Total cholesterol increased with age, while HDL-C remained steady. Both apo A1 and B levels increased with age. Apo A1 was positively correlated with HDL-C concentrations $(r=0.36, \quad \mathrm{p}=0.008)$. Apo $\mathrm{B}$ was highly positively correlated with the TC/HDL-C ratio $(r=0 \cdot 7, \mathrm{p} « 0 \cdot 001)$. The TC/HDL-C ratio was positively correlated with waist $(r=0 \cdot 29$, 
Table 5 Comparison of lipid profiles of total group, each major age group, and above and below 90th centiles of body mass index (BMI) and waist to hip ratio (WHR) (TC and $H D L-C$ in mmoll; apoproteins in $\mathrm{mg} / \mathrm{dl}$ ). Values are means (SD)

\begin{tabular}{|c|c|c|c|c|c|}
\hline & $T C$ & $H D L-C$ & $T C / H D L$ & apo $A 1$ & apo $B$ \\
\hline Total group & $\begin{array}{l}4.05(0.73) \\
(n=144)\end{array}$ & $\begin{array}{l}1 \cdot 32(0 \cdot 29) \\
(n=125)\end{array}$ & $\begin{array}{l}3.24(0.88) \\
(n=125)\end{array}$ & $\begin{array}{l}112 \cdot 03(22 \cdot 01) \\
(n=53)\end{array}$ & $\begin{array}{c}79.99 \\
(\mathrm{n}=53)\end{array}$ \\
\hline 15 Years & $\begin{array}{l}3.92(0 \cdot 70) \\
(n=24)\end{array}$ & $\begin{array}{l}1 \cdot 30(0 \cdot 25) \\
(n=19)\end{array}$ & $\begin{array}{l}3.20(0 \cdot 90) \\
(n=19)\end{array}$ & $\begin{array}{l}101 \cdot 20(17 \cdot 30) \\
(n=7)\end{array}$ & $\begin{array}{l}66 \cdot 40(13 \cdot 10) \\
(n=8)\end{array}$ \\
\hline 16 Years & $\begin{array}{l}4.01(0 \cdot 73) \\
(n=85)\end{array}$ & $\begin{array}{l}1 \cdot 32(0 \cdot 30) \\
(n=74)\end{array}$ & $\begin{array}{l}3 \cdot 20(0 \cdot 80) \\
(n=74)\end{array}$ & $\begin{array}{l}113.50(23.00) \\
(n=33)\end{array}$ & $\begin{array}{l}51.50(23.00) \\
(n=33)\end{array}$ \\
\hline 17 Years & $\begin{array}{l}4 \cdot 23(0 \cdot 75) \\
(n=32)\end{array}$ & $\begin{array}{l}1 \cdot 30(0 \cdot 29) \\
(n=30)\end{array}$ & $\begin{array}{l}3 \cdot 34(1 \cdot 00) \\
(n=30)\end{array}$ & $\begin{array}{l}114 \cdot 30(22 \cdot 20) \\
(n=12)\end{array}$ & $\begin{array}{l}86 \cdot 30(22 \cdot 70) \\
(n=12)\end{array}$ \\
\hline \multicolumn{6}{|r|}{ (2) - or } \\
\hline$>90 \%$ & $\begin{array}{l}4 \cdot 20(0 \cdot 90) \\
(n=15)\end{array}$ & $\begin{array}{l}1 \cdot 12(0 \cdot 09) \\
(\mathrm{n}=12)\end{array}$ & $\begin{array}{l}3 \cdot 88(1 \cdot 10)^{\star} \\
(n=12)\end{array}$ & $\begin{array}{l}126 \cdot 40(33 \cdot 00) \\
(\mathrm{n}=5)\end{array}$ & $\begin{array}{l}101.90(50 \cdot 00)^{\star} \\
(\mathrm{n}=5)\end{array}$ \\
\hline$<90 \%$ & $\begin{array}{l}4 \cdot 03(0 \cdot 70) \\
(n=128)\end{array}$ & $\begin{array}{l}1 \cdot 34(0 \cdot 09) \\
(n=113)\end{array}$ & $\begin{array}{l}3 \cdot 18(0 \cdot 80)^{\star} \\
(n=113)\end{array}$ & $\begin{array}{l}110 \cdot 50(20 \cdot 40) \\
(n=48)\end{array}$ & $\begin{array}{c}77 \cdot 80(17 \cdot 00)^{\star} \\
(\mathrm{n}=48)\end{array}$ \\
\hline \multicolumn{6}{|l|}{ WHR } \\
\hline$>90 \%$ & $\begin{array}{l}3.70(0 \cdot 60) \\
(n=14)\end{array}$ & $\begin{array}{l}1 \cdot 10(0 \cdot 21) \\
(n=9)\end{array}$ & $\begin{array}{l}3.40(0.60) \\
(n=9)\end{array}$ & $\begin{array}{c}88 \cdot 00 \\
(n=1)\end{array}$ & $\begin{array}{c}69 \cdot 00 \\
(n=1)\end{array}$ \\
\hline$<90 \%$ & $\begin{array}{l}4 \cdot 08(0 \cdot 70) \\
(n=129)\end{array}$ & $\begin{array}{l}1 \cdot 34(0 \cdot 30) \\
(n=116)\end{array}$ & $\begin{array}{l}3.20(0.90) \\
(n=116)\end{array}$ & $\begin{array}{l}112 \cdot 00(22 \cdot 00) \\
(n=52)\end{array}$ & $\begin{array}{l}80 \cdot 00(23 \cdot 00) \\
(n=52)\end{array}$ \\
\hline
\end{tabular}

$\mathrm{TC}=$ total cholesterol; HDL-C=high density lipoprotein cholesterol; apo=apoprotein $\star$ Significant difference at the 0.05 level.

$\mathrm{p}=0.03), \mathrm{BMI},(r=0 \cdot 28, \mathrm{p}=0.04)$, and WHR $(r=0 \cdot 25, \mathrm{p}=0 \cdot 07)$.

Girls with a BMI above the 90 th centile did not differ significantly in total cholesterol but had a lower HDL-C, which resulted in a significantly higher TC/HDL-C ratio (table 5). Apo B was also significantly higher in these girls $(p=0.02)$. Girls with a WHR above the 90th centile had both lower total cholesterol and lower HDL-C and thus the TC/HDL-C ratio did not differ significantly.

A value of $<5.0 \mathrm{mmol} / \mathrm{l}$ for total cholesterol and $>0.9$ for HDL-C has been recommended as desirable for 16 year old girls. ${ }^{45}$ Ten per cent of the total (14 girls) had a total cholesterol of $>5.0$; of these, 12 also had HDL-C measurements taken. The HDL-C of this group was significantly higher, at 1.50 (SD 0.43) $v 1.32$ $(0.29) \mathrm{mmol} / \mathrm{l}(\mathrm{p}=0.05)$ than in the group as a whole, but the greater difference in total cholesterol resulted in a higher TC/HDL-C ratio: $3.9(1.15) v 3.2(0.88)(\mathrm{p}=0.02)$. This group was not significantly different in BMI, WHR, or waist from the group as a whole. Only one girl satisfied the double risk factor of total cholesterol $>5.0$ and HDL-C $<0.9 \mathrm{mmol} / \mathrm{l}$.

\section{ASSOCIATION BETWEEN PHYSICAL ACTIVITY} AND LIPID PROFILES

The lipid values of subjects who were assessed as being above or below the average by all of the separate methods of categorising physical activity (including a comparison of the top and bottom scorers in the total activity score) were not significantly different (data not shown). However, there was a consistent trend for the more active group to have a lower TC/HDL-C ratio.

Table 6 Comparison of mean lipids values between smokers and non-smokers and girls of English speaking and non-English speaking background (ESB, NESB)

\begin{tabular}{llll}
\hline Group & TCS $(95 \% C I)$ & HDL-CS $(95 \% C I)$ & TC/HDL-CS $(95 \% C I)$ \\
\hline Non-smoker & $4 \cdot 18(4.05 \text { to } 4.32)^{\star}$ & $1.34(1.28$ to 1.39$)$ & $3.26(3.10$ to 3.43$)$ \\
Smoker & $3.69(3.39 \text { to } 3.99)^{\star}$ & $1.24(1.12$ to 1.36$)$ & $3.14(2.78$ to 3.5$)$ \\
ESB & $4.02(3.88$ to 4.15$)$ & $1.32(1.26$ to 1.37$)$ & $3.16(3.00$ to 3.33$)$ \\
NESB & $4.43(4.15$ to 4.72$)$ & $1.33(1.21$ to 1.45$)$ & $3.58(3.24$ to 3.92$)$ \\
\hline
\end{tabular}

TC=total cholesterol; HCL-C = high density lipoprotein cholesterol; $\mathrm{CI}=$ confidence interval ${ }^{\star} \mathrm{p}<0.01$ level.

SAdjusted for BMI and WHR.
ASSOCIATION BETWEEN SMOKING HABITS AND LIPID PROFILES

Preliminary analysis showed that the total cholesterol in smokers was lower than in nonsmokers $(p=0.02)$. This was partly explained by lower HDL-C in smokers $(p=0.06)$. Since smokers had slightly greater BMI and WHR than non-smokers the lipids were adjusted for these variables. The adjusted levels of total cholesterol in smokers was lower than in nonsmokers and again this was largely explained by a lower level of HDL-C in smokers (table 6).

\section{ASSOCIATION BETWEEN FIRST LANGUAGE}

SPOKEN AT HOME AND LIPID PROFILES

Since girls from non-English speaking backgrounds had a more central distribution of body fat, the total cholesterol and HDL-C levels were adjusted for BMI and WHR before lipid profiles were compared. A comparison of these adjusted values (table 6) showed that these girls had a higher total cholesterol than girls from English speaking backgrounds. HDL-C concentrations were similar in the two groups; thus the TC/HDL-C ratio was higher in girls of non-English speaking background.

\section{CORRELATION ANALYSIS}

HDL-C was negatively correlated with WHR $(r=-0.21, \quad \mathrm{p}=0.017)$. No significant correlations were found between lipids and the various measures of physical activity.

\section{Discussion}

A significant proportion of chronic disease in adulthood can be viewed as having its origins in childhood, and these origins have a strong lifestyle component, including body fatness, physical activity, and smoking. This study provides evidence for cardiovascular risk trends in a population group (adolescent females) that has not previously received much attention in this area.

A comparison of US data from NHANES I ${ }^{43}$ and the Australian ACHPER data ${ }^{4}$ has confirmed that Americans are generally fatter. ${ }^{46}$ Australian schoolgirls are lighter than the American girls in the NHANES I study in each of the three major age groups with the exception of the 90th centile of the 16 and 17 year olds. The ACHPER data finish at age 15; the 15 year old schoolgirls are close to the ACHPER below the 50th centile, but their values are greater in the higher percentile bands.

Taking a BMI value greater than the 90th centile as a criterion of overweight, ${ }^{44}$ there was a decrease in the percentage of overweight 16 and 17 year olds if ACHPER and NHANES I cut-offs are used, resulting in a lower prevalence of overweight in the Australians. Questions asked by the girls during follow up discussions at one school revealed a widespread fear of weight gain and some concern about the dangers of developing eating disorders while trying to maintain or lose weight.

A WHR measurement of 0.8 has been 
suggested as a threshold for risk of coronary heart disease in adult women ${ }^{47}$; no reference ranges for WHR are available for Australians under the age of 18 . The number of schoolgirls with WHR $>0.8$ corresponds to the 90th centile band. WHR remained constant across age groups and is similar to that found in young adult women, ${ }^{8}$ indicating that pubertal changes in WHR are largely completed by age 15. ${ }^{48}$ The average age to reach menarche in Australia is 12.5 and it can be assumed that at least $95 \%$ of the subjects are postmenarchial.

Lipid values in the study subjects are generally similar to those described in studies which include at least some subjects of similar age. ${ }^{34950}$ The concentrations of apo A1 (the main protein carrier of HDL-C) in a subset of the study population are almost identical to those found in other studies of similarly aged subjects. 4950 Both HDL-C and apo A1 remained constant across age groups. This finding most probably reflects established postpubertal status, as apo A1 drops markedly after puberty in girls. ${ }^{49}$ The atherogenic LDL cholesterol cannot readily be measured in an epidemiological setting; however, apo $B$, which carries LDL cholesterol, was measured in a subset of the study population and found to be highly correlated with the main lipid index of atherogenicity, the ratio of total cholesterol to HDL-C.

Two potential confounding variables for lipid measurements in this study are that subjects were not fasted and that oral contraceptive use was not determined. Fasting primarily affects triglyceride levels and has little effect on total cholesterol or HDL-C. ${ }^{51}$ The effect of oral contraceptive use is likely to be minor. In one study in young women no difference was found in mean total cholesterol with oral contraceptive use and only a 0.04 $\mathrm{mmol} / 1$ difference in HDL-C was noted. ${ }^{8}$

The significantly higher TC/HDL-C ratio and apo B in girls above the 90th centile for BMI but not in those above the 90th centile for WHR suggests that in this young relatively lean population, total adiposity appears to be associated with a more atherogenic lipid profile than the distribution of body fat (since WHR is closely correlated with visceral fat mass as measured by computerised axial tomography ${ }^{52}$ it may be used as an indicator of visceral fat in epidemiological studies ${ }^{53}$ ).

Smoking and physical activity are known independent risk factors for coronary heart disease. In this population smoking increased with age and the prevalence of smoking in the older girls approached the national average for this age group. ${ }^{18}$ The lower total cholesterol of the smokers is partly explained by a reduction in HDL-C which persists after adjustment for anthropometric variables. It is of increasing concern that smoking rates in adolescent girls are not declining in Australia despite extensive public education programmes. Smoking is often viewed as a weight control mechanism in adolescent girls and this belief is likely to override any health messages, including those related to lipid profiles. The finding of lower total cholesterol in smokers emphasises the importance of considering the lipid subfractions in cholesterol screening.

There is no gold standard to assess physical activity in an individual. The study method is relatively broad but both vigorous and nonvigorous exercise tended to be associated with a higher ratio of total cholesterol to HDL-C. In particular, girls from non-English speaking backgrounds spent less time in vigorous exercise and had a higher TC/HDL-C ratio. It is likely that considerations of modesty and cultural practice influence physical activity in this group. Schools may need procedures to ensure equity of access to healthy physical activity in young women from non-English speaking backgrounds.

The lipid profile was generally healthy in these adolescent girls. Even in the higher ranges of $\mathrm{BMI}$, where the greatest differences were observed, the mean TC/HDL-C ratio still indicates comparatively low risk. However, several risk trends are apparent which suggest some pertinent school health education concerns. These include discouraging smoking and providing equity of access to exercise and physical activity. In the final analysis it is worth emphasising that ischaemic heart disease, a chronic disease of which smoking is a major risk factor, is the main cause of death of women in Australia and that the lifestyle components which influence cardiovascular disease are better treated in adolescence than in later life.

1 Berenson GS. Cardiovascular risk factors. In: Berenson GS, ed. Childhood perpectives on cardiovascular risk in early life. New York: Raven Press, 1986.

2 Hickie JB, Sutton J, Russo P, Ruys J, Kraegen EW. Serum cholesterol and serum triglyceride levels in Australian adolescent males. Med f A ust 1974; 1: 825-8.

3 Boulton TJC, Hill GN. Serum cholesterol levels from birth to maturity. Med $\mathcal{F}$ Aust 1980; 1: 20-2.

4 ACHPER. Australian Council of Health, Physical Education and Fitness Survey. Adelaide: ACHPER Publications, 1985.

5 Glicksman MD, Dwyer T, Wlodarczyk J. Differences in modifiable cardiovascular disease risk factors in Australian modifiable cardiovascular disease risk factors in Australian Med 1990; 19: 219-304.

6 Jenner DA, Dunbar D, Vandongen R, Belin L. Reflotron cholesterol measurements in 1112 Australian children cholesterol measurements in 1112 Austrat

7 Risk Factor Prevalance Study Management Committee. Risk factor prevalence study: survey No 2, 1983. Canberra: National Heart Foundation of Australia, 1986.

8 Risk Factor Prevalance Study Management Committee. Risk factor prevalence study: survey No 3, 1989. Canberra: National Heart Foundation of Australia and Australian Institute of Health, 1990.

9 American Heart Association. 'The cholesterol facts'; a summary of the evidence relating dietary fats, serum cholesterol and coronary heart disease. Circulation 1990; 81: 1721-33.

10 Gordon DJ, Knoke J, Probstfield JL, Superko R, Tyroler HA. High-density lipoprotein cholesterol and coronary heart disease in hypercholesterolemic men: the Lipid Research Clinics coronary primary prevention trial. Research Clinics coronary prit
Circulation 1986; 74: 1217-25.

11 Kannel WB, Wilson PWF. Efficacy of lipid profiles in prediction of coronary heart disease. Am Heart $\mathcal{f} 1992$; 124:
Annel WB, Wilson PWF. Efficacy of lipid profiles in prediction

12 Stampfer MJ, Sacks FM, Salvine S, Willett WC, Hennekens CH. A prospective study of choleserol, apoproteins, and the risk of myocardial infarction. N Engl $\mathcal{F} M e d 1991 ; 325$ 373-81.

13 Buring JE, O'Connor GT, Goldhaber SZ, et al. Decreased $\mathrm{HDL}_{2}$ and $\mathrm{HDL}_{3}$ cholesterol, apoA-1 and apoA-II, and increased risk of myocardial infarction. Circulation 1992 85: 22-9.

14 Criqui M, Wallace RS, Weiss G. Cigarette smoking and plasma high-density lipoproteins. Circulation 1980;62 (suppl): 70-6.

15 Brischetto CS, Connor WE, Connor SL, Matarazzo JD. Plasma and lipid lipoprotein profiles of cigarette smokers from randomly selected families: enhancement of hyperlipidemia and depression of high density lipoprotein. $A m \mathcal{F}$ Cardiol 1983; 52: 675-80.

16 Freedman DS, Srinivasan SR, Shear CL, et al. Cigarette smoking inhalation and longitudunal changes in serum 
lipids and lipoproteins in early adulthood: the Bogaslusa heart study. Am F Epidemiol 1986; 124: 207-19.

17 Hill DJ, White VM, Gray NJ. Australian patterns of tobacco smoking in 1989. Med $\mathcal{f}$ Aust 1991; 154: 797-801.

18 Hill D, White V, Segan C. Prevalence of cigarette smoking among Australian seconday school students in 1993. (Preliminary Report 1-8.) Victoria. Centre for Victoria, 1994.

19 Taylor R. Risks of premature death from smoking in 15year-old Australians: the estimated risk of premature year-old Australians: the estimated risk of premature death from ever smoking in a 15-yea
Public Health 1993; 17: 358-64.

Public Health 1993; 17: 358-64.
20 Haskell W, Leon A, Caperson C. Cardiovascular benefit and assessment of physical activity and physical fitness in and assessment of physical activity and physical fitness

21 Adner MM, Castelli WP. Elevated high density lipoprotein levels in marathon runners. $\mathfrak{f} A M A$ 1980; 243: 534-6.

22 Sedgwick A, Thomas D, Davies M, Baghurst K, Rouse I. Cross sectional and longitudunal relationship between physical fitness and risk factors for coronary heart disease. f Clin Epidemiol 1989; 42: 1989-2000.

23 Bauman A, Owen N. Habitual physical activity and cardiovascular risk factors. Med $¥$ A ust 1991; 154: 22-8.

24 Koyama H, Ogawa M, Suzuki S. Relationship between total cholesterol and high-density lipoprotein cholesterol and the effects of physical exercise, alcohol consumption, cigarette smoking and body mass index. $₹ \mathrm{Nutr} S \mathrm{Sci}$ Vitaminol 1990; 36: 377-85.

25 Sedgwick AW, Davidson AH, Taplin RE, Thomas DW. Effects of physical fitness and risk factors for coronary heart disease in men and women. Aust NZ Med F 1984; 14: 208-21.

26 Sedgwick AW, Davidson AH, Taplin RE, Thomas DW. Effects of physical fitness and risk factors for coronary heart disease in previously sedentary women: a five years longitudinal study. Aust NZ Med F 1988; 18: $600-5$.

27 Boulton TJC. Nutrition in childhood and its relation to early somatic growth, body fat, blood pressure, and physical fitness. Acta Paediatr Scand 1981; suppl: 284 .

28 Hubert HB, Feinleib M, McNamara P, Castelli MD Obesity as an independent risk factor for cardiovascular disease: a 26-year follow-up of participants in the Framingham heart study. Circulation 1983; 67: 968-77.

29 Larsson B, Svardsudd K, Welin L, Wilhelmsen L, Bjorntorp $P$, Tibblin G. Abdominal adipose tissue distribution, obesity and risk of cardiovascular disease and death: 13 year follow-up of participants in
1913. BMF 1984; 288: 1401-4.

30 Lapidus L, Bengtsson C, Larsson B, Pennert K, Rybo E. Distribution of adipose tissue and risk of cardiovascular disease and death: a 12 year follow-up of participants in disease and death: a 12 year follow-up of participants in
the population study of women in Gothenburg, Sweden. the population study of won

31 Stokes II, Garrison RJ, Kannel WB. The independent contributions of various indices of obesity to the 22-year incidence of coronary heart disease: the Framingham heart study. In: Vague J, Bjorntorp P, Guy GB, eds. Metabolic complications of human obesities. Amsterdam: Elsevier, 1985: 49-57.

32 Ducimetiere P, Richard J, Cambien F. The pattern of subcutaneous fat distribution in middle-aged men and the risk of coronary heart disease: the Paris prospective study. Int 7 Obes 1986; 10: 229-40.

33 Donahue RP, Abbott RD, Bloom E, Reed DM, Yano K. Central obesity and coronary heart disease in men. Lancet 1987; i:822-4.

34 Terry RB. Waist/hip ratio, body mass index and premature cardiovascular disease mortality in US Army veterans during a 23 year follow-up study. Int $\mathcal{f}$ Obes 1992; 16: 417-23.
35 Marti B, Suter E, Riesen WF, Tschopp A, Wanner HU. Anthropometric and lifestyle correlates of serum lipoprotein and apolipoprotein levels among normal nonsmoking men and women. Atherosclerosis 1989; 75: 111-22.

36 Perusse L, Despres JP, Tremblay A, et al. Genetic and environmental determinants of serum lipids and lipoproteins in French Canadian families. Arteriosclerosis 1989; 9: 308-18.

37 Court JM, Dunlop M, Reynolds M, Russell J, Griffiths L. Growth and development of fat in adolescent school children in Victoria. Part 2. Influence of ethnic, geographic and socio-economic factors. Aust Paediatr $\mathcal{F}$ 1976; 12: 305-12.

38 Court JM. The development of obesity in childhood. Med $\mathcal{F}$ Aust 1979; 2: 248-50.

39 Philips S, Wyndham L, Shaw J, Walker SF. How accurately does the Reflotron dry-chemistry system measure total cholesterol levels when used as a community screening device? Med f Aust 1988; 149: 122-5.

$40 \mathrm{Ng} \mathrm{R}$, Sparks K, Statland B. Direct measurement of high density lipoprotein cholesterol by the Reflotron assay with no manual precipitation step. Clin Chem 1991; 37: 435-7.

41 Abacus Concepts, Statview. Berkeley: Abacus Concepts Inc, 1992.

42 Kleinbaum DG, Kupper LC, Muller KE. Applied regression analysis. Boston: Duxbury Press, 1988.

43 Harlan WR, Landis R, Flegal KM, Davis CS, Millar ME. Secular trends in body mass index in the United States 1960-80. Am ₹ Epidemiol 1988; 128: 1065-74.

44 Hammer LD, Kreamer HC, Wilson DM, Ritter PL, Dornbusch SM. Standardised percentile curves of body-
mass index for children and adolescents. Am $\mathcal{F}$ Dis Child mass index for child

45 Macck M, Rutenfranz J, Bell R. Integrated risk assessment for cardiovascular diseases: a methodological approach In: Oseid S, Carlsen $\mathrm{K}$, eds. Children and exercise XIII. Champaign: Human Kinetics Books, 1989: 247-54.

46 Harvey PWJ, Althaus MM. The distribution of body mass index in Australian children aged 7-15 years. Aust $\mathcal{F}$ Nutr Dietet 1993; 50: 151-3.

47 Despres JP. Obesity and lipid metabolism: relevance of body fat distribution. Curr Opin Lipidol 1991; 2: 5-15.

48 Martinez E, Devesa M, Bacallao J, Amador M. Percentiles of the waist-hip ratio in Cuban scholars aged 4.5-20.5 years. Int $\mathcal{F}$ Obes 1994; 18: 557-60.

49 Alaupovic P, McConathy WJ, Fesmire J, Tavella M, Bard J. Profiles of apolipoproteins and apolipoprotein B-containing lipoprotein particles in dyslipoproteinemias. Clin Chem 1988; 34: B13-27.

50 Gozlan O, Gross D, Gruener N. Lipoprotein levels in newborn and adolescents. Clin Biochem 1994; 27: 305-6.

51 Van Beurden E, James R, Montague D, Christian J, Dunn T. Community-based cholesterol screening and education T. Community-based cholesterol screening and education to prevent heart disease: five-year results of the North
Coast cholesterol check campaign. Aust $\mathcal{f}$ Public Health Coast cholesterol

52 Freland M, Despres JP, Tremblay A, et al. Assessment of adipose tissue distribution by computer axial tomography in obese women: association with body density and anthropometric measurements. Br $\mathcal{f}$ Nutr 1989; 62: $139-48$.

53 Pouliot MC, Despres JP, Lemieux S, et al. Waist circumference and abdominal sagittal diameter: best simple anthropometric indexes of abdominal visceral adipose tissue poccumulation and related cardiovascular risk in men and women? Am $f$ Cardiol 1994; 73: 460-8.

54 Shimokata H, Muller D, Anders R. Studies in distribution of body fat. Effects of cigarette smoking. $\mathscr{F} A M A$ 1988; 261: 1169-73. 